\title{
Strength Enhancement of Fibre Reinforced Peat with Fly Ash as Stabilized Subgrade Layer
}

\author{
Siti Rozana Romali ${ }^{1, a}$, Norazzlina M.Sa'don ${ }^{2, b^{*}}$ \\ and Abdul Razak Abdul Karim ${ }^{3, c}$
}

\author{
1,2,3Faculty of Engineering, Universiti Malaysia Sarawak, 94300 Kota Samarahan, Malaysia. \\ ${ }^{1}$ Politeknik Kuching Sarawak, KM 22, Jalan Matang, 93050 Kuching, Sarawak, Malaysia. \\ acctrozana1410@gmail.com, ${ }^{\mathrm{b} *}$ msazzlin@unimas.my, cakarazak@unimas.my
}

\begin{abstract}
Keywords: CBR; fly ash; nylon fibre; peat; unconfined compressive strength.
\end{abstract}
\begin{abstract}
High content of organic matter and fibre within peat results in a high degree of porosity; causing peat to have low bearing capacity. This study focuses on the application of nylon fibre as reinforcing material with fly ash as the chemical stabilizer to enhance the strength of the peat. The standard proctor tests were conducted to obtain the optimum moisture content (OMC) for all samples in which these OMC is then used for sample preparation of both the Unconfined Compressive Strength (UCS) tests and the California Bearing Ratio (CBR) tests. Samples for this study were categorized into control samples and modified samples for comparison purposes. Additives that were being used in this study are $5 \%$ cement, $5 \%$ nylon fibre and $10 \%, 15 \%$, and $20 \%$ fly ash. For UCS test, the samples were cured for 7, 14, 28 and 56 days, whereas only 7 days of curing for CBR test. Throughout the study, improvements of strength were observed where sample added with 5\% cement, $5 \%$ nylon fibre and 10\% fly ash recorded the highest compressive strength value, of $123.71 \mathrm{kN} / \mathrm{m} 2$. As for CBR test, all samples exceeded the minimum requirement of $12 \%$ CBR value for subgrade design recommended by JKR Malaysia with the highest CBR value obtained from samples added with $5 \%$ cement and $10 \%$ fly ash. The CBR values were $43.85 \%$ and $43.70 \%$ for unsoaked and soaked condition, respectively.
\end{abstract}

\section{Introduction}

Differ from other soils which are consist of only soil fragments, peat contains incomplete decomposition of organic matter; the reason for it to be highly fibrous with the potential to hold up a significant amount of water, thus having low bearing capacity. The ability of peat to compress excessively is a major obstacle in construction engineering due to the tendency of peat to settle whenever loadings are applied; making it to be unsuitable for any form of construction. Some development undergoes on peat has faced numerous engineering difficulties which are due to the uneven settlement as well as sinking of the ground surface [1]. In the early days of construction, development of peatlands was highly unrecommended [2]. However, due to rapid development nowadays, and the need for infrastructures in areas that are predominantly covered by peatlands, researchers started to come out with various solutions to deal with peat so that it is feasible for construction. The most typical approach when developing structure on peat is by clearing away the peat and switching it with other suitable soils or material; however, it does not seem feasible enough when dealing with a peat of significant depth [3]. Peat reinforcement and peat stabilization are two techniques known that can enhance the properties of the soils which helps to sustain loading. Thus, this research is implemented to study the outcome of using nylon fibre as peat reinforcement combined with fly ash, which has been scientifically proven as the stabilizing agent for subgrade layer.

Peatland in Sarawak are mostly occupying the main wetlands and along the shorelines as well [4]. $89 \%$ of peatland in Sarawak are over $1 \mathrm{~m}$ deep [2], thus making it a challenge to construction. This is on the account of peat famously known for being problematic soil to work with due to its properties. Owing to this, many established studies have proposed numerous alternatives to stabilize and strengthen peat which includes the use of waste materials. However, the use of nylon fibre from waste 